\title{
O paradoxal estatuto do conhecimento jornalís- tico: entre a desconsideração e o protagonismo do saber produzido pelas notícias nas sociedades modernas
}

\author{
Isabelle Anchieta*
}

\section{Resumo}

O conhecimento jornalístico produz um debate paradoxal: por um lado é a forma mais adequada de conhecer o presente e os fatos distantes tornando-se central nas sociedades modernas; por outro é tido como um conhecimento insuficiente, fragmentado e ideologicamente comprometido sobre realidade social. Neste artigo questionaremos: qual é, afinal, o estatuto do conhecimento jornalístico nas sociedades modernas? Iremos inserir a discussão no contexto da crise das narrativas e da ciência como verdade. Seus efeitos atingem o jornalismo de forma particular e instauram um dilema: se ele não pode legitimar-se em sua cientificidade estaria assim mais próximo do conhecimento do senso comum? Para tanto iremos comparar duas perspectivas teóricas fundadoras sobre o conhecimento noticioso: a do alemão Tobias Peucer, no século 17, e do americano Robert Park, no século 20. Nessa comparação nos interessa observar o que muda, mas especialmente o que permanece nas práticas noticiosas para, enfim, compor um ethos do conhecimento jornalístico.

Palavras chave: Conhecimento Jornalístico. Crise dos Metarrelatos. Legitimidade. Tobias Peucer. Robert Park.

\footnotetext{
* Professora do Curso de Jornalismo, Faculdade de Comunicação Social, Universidade Mackenzie em São Paulo, São Paulo-SP, Brasil. Articulista da revista Mente e Cérebro (Scientific American), São Paulo-SP. Doutoranda em Sociologia na FFLCH da Universidade de São Paulo (USP), Brasil. Mestre em Comunicação Social pela UFMG e bacharel em jornalismo pela PUC Minas. Tem dois livros publicados: Mapeamento do ensino do Jornalismo Cultural no Brasil (prêmio Itaú Cultural de jornalismo) e Sete Propostas para o Jornalismo Cultural. Foi âncora do telejornal da Rede Globo Minas. E-mail: isabelleanchieta@gmail.com
} 


\section{The paradoxical situation of journalistic knowledge: among the callousness and the leading role of the knowledge produced by the news in modern societies}

\section{Abstract}

The knowledge of journalism debate produces a paradox: on the one hand, it is the most appropriate way to meet the present and historical events in modern societies, on the other hand, is considered insufficient knowledge, fragmented and ideologically committed to the social reality . In this article we ask: Which is, after all the place of knowledge generated for journalism in modern society? Let's get into the discussion in the context of the crisis of traditional knowledge and science as truth. Its effects reach particularly the form of journalism and creates a dilemma: whether journalism can not be legitimized in scientific terms would then be closer to the knowledge based on common sense? For that, compared two theoretical perspectives on knowledge news: the German Tobias Peucer, seventeenth century, and the American Robert Park, of the twentieth century. In this comparison we are interested in observing the changes, but especially that which remains in journalistic practices to finally establish the ethics of journalistic knowledge.

Keywords: Knowledge journalistic. Accounts Metarrelatos. Legitimacy. Tobias Peucer. Robert Park.

\section{La situación paradoxal de los conocimientos periodísticos: entre la desconsideración y el papel protagónico de los conocimientos producidos por las noticias, en las sociedades modernas}

\section{Resumen}

El conocimiento periodístico produce un debate paradoxal: por un lado, es la forma más adecuada para conocer el presente y los acontecimientos históricos en las sociedades modernas, por otra parte, es considerado un conocimiento insuficiente, fragmentado e ideológicamente comprometido con la realidad social. En este articulo nos preguntamos: ¿Cual es, después de todo el lugar del conocimiento generado por el periodismo en las sociedades modernas? Vamos a entrar en la discusión en el contexto de la crisis de los conocimientos clásicos y la ciencia como verdad. Sus efectos alcanzan de forma particular al periodismo y se crea un dilema: si el periodismo no puede legitimarse en términos científicos estaría entonces más próximo del conocimiento basado en el sentido común? Para eso se compararan dos perspectivas teóricas sobre el conocimiento noticioso: la del alemán Tobías Peucer, del siglo 17, y la del estadounidense Robert Park, del siglo 20. En esta comparación nos interesa observar los cambios, pero especialmente lo que permanece en las practicas periodísticas para establecer finalmente la ética del conocimiento periodístico.

Palabras clave: Conocimientos Periodísticos. Crisis de los Meta relatos. Legitimidad. Tobías Peucer. Robert Park. 


\section{Introdução}

M arginalizado ora como uma técnica de transmissão de informação, ora como uma forma menor de conhecimento, o jornalismo adquire, contrariamente, mais vigor e presença no arranjo social moderno. Assistimos a uma profusão de notícias e a emergência de novos meios. Mas, a dúvida persiste: o jornalismo é ou não uma forma legítima de conhecimento? Tal incerteza produz efeitos concretos sobre a área. Dentre eles: o debate da necessidade ou não de uma formação superior, as condições de trabalho e sua organização como um campo profissional.

Nosso objetivo é compreender se o jornalismo produz conhecimento e qual seria ele, suas singularidades e como torna-se significativo para as sociedades modernas. Para tanto realizamos uma revisão bibliográfica do tema. Primeiro iremos contextualizar a crise das grandes narrativas (Religião, História e Ciência), especialmente por meio das críticas de Nietzsche e Lyotard. Em seguida, iremos demonstrar os efeitos dessa crise e como ela atinge o jornalismo de maneira particular. Momento em que iremos apresentar e comparar duas perspectivas fundantes para a configuração de um campo de saber próprio ao jornalismo: a do alemão Tobias Peucer, no século 17, e do americano Robert Park, no século 20. Textos que tanto revelam as singularidades de um saber universal e atemporal, como dão marcas do estatuto social do conhecimento jornalístico frente a contextos históricos diversos.

Por fim, problematizaremos quais são os diálogos, mas especialmente quais são as diferenças entre o jornalismo e outras formas de saber. $\mathrm{O}$ que constitui o jornalismo como uma área de conhecimento sobre o presente e como esse conhecimento tornase fundamental nas sociedades modernas.

\section{A crise dos metarrelatos e seus efeitos sobre o jornalismo}

"Eu próprio não creio que jamais alguém tenha olhado para o mundo com uma suspeita tão profunda" (NIETZSCHE, 2006, p. 19).

O fim da modernidade é marcado pela crise das grandes narrativas, entre elas a cristã; a científica e a histórica. $\mathrm{O}$ cristianismo 
é desmistificado como sendo uma versão para explicar a existência divina e não uma verdade inquestionável. Seu principal crítico, o alemão Friedrich Nietzsche afirma que "o vale de lágrimas não fora Deus que criara" (NIETZSCHE, 2006, p.44). Para ele, o cristianismo é uma narrativa doutrinária criada pelos religiosos que nega ao homem sua potência afirmativa de viver ao impor uma vida de privações e sofrimentos em prol de um devir ilusório (o paraíso). Completa, "o céu está no homem, como o inferno está. Amar a vida é a maneira mais nobre de orar" (NIETZSCHE, 2006, p.45). Assim, a sua famosa afirmação de que "Deus morreu" refere-se, portanto, a denúncia da narrativa cristã como uma doutrina que nega moralmente a vida em sua sensibilidade, prazer e fruição. $\mathrm{O}$ que fica evidente quando faz a seguinte distinção e consideração: "O único cristão morreu na cruz" (NIETZSCHE, 2006, p.45). O que se encerra não é tanto a possibilidade de uma existência divina e sublime da vida, mas o seu aprisionamento em uma explicação unitária, moral e negadora da vida.

Outra narrativa que entra em crise - denunciada igualmente como forma dogmática - é a Ciência. Criticada como uma nova forma de fé, ela passa a ser percebida não mais como uma verdade irrefutável, mas como uma forma de selecionar, ordenar, classificar e hierarquizar racionalmente o real. Para Lyotard, a Ciência perde atualmente sua relação com a ideia de verdade e espírito razoável, para ser compreendida como uma informação ou tecnologia intelectual, desprovida de uma moral em si. Nesse sentido, "o que está em questão não é mais a verdade, mas o desempenho" (LYOTARD,1993, p.17).

A História também é descortinada em suas limitações narrativas. Para o italiano Gianni Vattimo, "não existe uma história única; existem sim imagens do passado propostas por pontos de vista diversos e é ilusório pensar que existe um ponto de vista supremo" (VATTIMO, 1992, p.11). E, se não existe um ponto de vista supremo e uma narrativa ordenadora para contar a História, essa perde seu desenho linear e evolucionista. Pois, se não existe um curso unitário da História humana, não podemos dizer que estamos progredindo.

Os efeitos dessa crise dos metarrelatos foram sentidos em todas as formas narrativas, mesmo as tidas como "menores". Den- 
tre elas: o jornalismo. $O$ espelhamento do real, a objetividade e a imparcialidade como pressupostos de cientificidade da notícia recebem duras críticas da perspectiva teórica emergente que toma as práticas sociais e as linguagens como construções. Mas, a ordem de grandeza da crise da notícia possui uma particularidade frente aos metarrelatos, na medida em que o jornalismo é considerado um conhecimento menos rigoroso. Inicia-se aqui um dilema para a área, pois se o jornalismo não pode mais se apoiar na "cientificidade fraca" do seu discurso de espelhamento do real, seria ele mais próximo do conhecimento produzido pelo senso comum? Qual, afinal, o estatuto social do conhecimento jornalístico nas sociedades modernas?

\section{Jornalismo: aproximações e diferenças com o senso comum}

A primeira tentativa de definir um lugar particular para o conhecimento jornalístico acontece no final do século 17, em 1690, na Alemanha, na tese de doutorado do erudito, estudioso de teologia e medicina, Tobias Peucer, na Universidade de Leipzig. Ainda pouco conhecida, a obra do alemão intitulada "De Relationibus Novellis" (Os relatos de novidades) tenta definir as notícias em comparação com a História. Em um primeiro momento afirma que a os relatos noticiosos são um gênero Histórico (especialmente o que descreve como História desordenada), mas, mais a frente faz críticas severas a esse tipo de novo relato situando-o em comparação e inferioridade ao relato Histórico.

Para tanto a subdivide em três formas diversas: 1) Cronológica; 2) Lógica e 3) Desordenada. A primeira delas seria uma forma de narrar os acontecimentos que "se ordena como um fio contínuo, conservando a sucessão precisa dos fatos históricos. Esta forma é denominada universal, particular ou singular" (PEUCER, cap.III, p.15, 2005). Já a de ordem lógica, seria ordenada, não mais pela ordem do tempo, mas a ordem estabelecida por um critério. "Uma determinada ordem os fatos ou as palavras escolhidas e dignas de serem contadas que se extraiu separadamente da narração contínua dos fatos históricos. Parece pertencer a esta forma da história as 'coisas esparsas` (tá sporáden) de Aristógenes; igualmente as his- 
tórias sem ordem de Pescenni Fest, das quais relembra Lactâncio, Livro I, De fals" (PEUCER, cap. III, p.15, 2005).

Já a terceira forma de História, a qual Peucer aproxima dos relatos noticiosos seria a História desordenada ou confusa. "Os gregos chamam-na de miscelânea (symmictica), ou seja, 'história variada' ou multiforme (poikiíle radena pandodapé história): dado que não há também nessa forma nenhum critério de ordem, é chamada também de coisas desordenadas (átacta). Foi desta forma que escreveu Aristóteles a sua obra, segundo o testemunho de Laercio, livro V, p.314” (PEUCER, cap. III, p.15, 2005).

Para Peucer, "esta última classe ou tipo de relationes (relatos) são relatos periodísticos (relationes nouvealle) que contêm a notificação de coisas diversas acontecidas recentemente em qualquer lugar que seja" (PEUCER, cap. IV, p.16, 2005). Continua afirmando que "estes relatos, com efeito, não tem mais em conta a sucessão exata dos fatos que estão inter-relacionados e suas causas, limitando-se somente a uma simples exposição, unicamente a bem do reconhecimento dos fatos históricos mais importantes, ou até mesmo misturam coisas de temas diferentes" (PEUCER, cap. IV, p.16, 2005).

Ao tentar descrever o que caracteriza os relatos noticiosos Peucer, ao contrário de aproximar o jornalismo, acaba o localizando em oposição a História, ora de forma elogiosa, ora crítica.

Não afirmaria absolutamente que a utilidade dos periódicos seja tão grande como a da História escrita com bom senso, dado que os autores daqueles se encontram quase desprovidos daquilo que é necessário para estabelecer a história escrita, com conhecimento dos fatos, competência, juízo elevado, documentos autênticos obtidos de arquivos não suspeitos e, finalmente a linguagem e estilo adequados à história (PEUCER, 2005, p.27).

A primeira vista o trecho pode parecer muito duro com o jornalismo e os jornalistas da época. No entanto, temos de relativizar tal impressão na medida em que há também um importante e inaugural esforço de Peucer em legitimar, singularizar e, especialmente, orientar o trabalho jornalístico. Oscila, assim, entre uma crítica à superficialidade do conhecimento produzido pelos relatos noticiosos de sua época e a descrição da emergência de um campo profissional - ainda não denominados de jornalismo 
e de jornalistas. Uma inconstância que pode ser tomada como um sintoma das mudanças sociais e das práticas noticiosas. Vale mencionar que é exatamente no contexto em que Peucer escreve sua tese, no final do século 18 , que os jornais e revistas tornamse potencialmente um ramo comercial em um contexto em que o capitalismo está emergindo, na transição de uma monarquia católica para uma burguesia protestante.

Os periódicos tornam-se os veículos ideais para legitimar os novos valores burgueses incentivando a circulação da informação e do conhecimento. Geridos por pessoas desvinculadas de crenças religiosas, geralmente ex-pastores calvinistas (laicos), os periódicos tornam-se importantes instrumentos de ruptura com uma sociedade secularizada e de legitimação do espírito burguês emergente marcado pela racionalidade e cientificidade da época. "O dito nada é sagrado acabou por caracterizar a carreira jornalística. Frente à furiosa cobiça de novidade e sede generalizada de notícias, os esforços dos moralistas católicos (...) se revelaram pouco úteis” (TAMBOSI, 2005, p.56)

As publicações migram da Itália para países do norte da Europa impulsionados pelo Renascimento e pela Reforma. $\mathrm{Na}$ Alemanha, temos o surgimento do Avisa Relation oder Zeitung e o Relation aller fürnemmen und gedenckwürdigen Historien (1609); na Inglaterra o The Corante (1621); na França o primeiro jornal, La Gazette (1631); em língua portuguesa, temos o A Gazeta, de Lisboa Portugal em (1641), na Suécia surge o Post-och Inrikes Tidningar (1645), que curiosamente é o jornal mais antigo do mundo ainda em circulação. Já o primeiro jornal diário do mundo "Einkommende Zeitungen" (Notícias Recebidas) surge em Leipzig, cidade alemã em que Peucer defende sua tese de doutoramento.

O esforço pioneiro de Peucer está em tentar estabelecer um lugar característico para esses "relatos de novidades", mesmo que manifeste sua desconfiança sobre o seu alcance. Para tanto ele descreve cinco características gerais observadas nos jornais de sua época: "os jornais contêm a notificação de coisas diversas acontecidas recentemente em qualquer lugar que seja, coisas essas que são 'novas', têm certa utilidade e atualidade e satisfazem a curiosidade humana" (PEUCER,2001). 
Com essa descrição dos jornais, Peucer evidencia cinco características das notícias: 1) pode haver notícias sobre tudo; 2) as notícias referem-se a acontecimentos atuais; 3) as notícias trazem novidades; 4) as notícias são úteis; e 5) muitas notícias têm sucesso porque satisfazem a curiosidade humana (SOUSA, 2005, p.5). Curiosidade que, segundo Peucer, distingue-se da curiosidade típica do conhecimento rigoroso o que fica evidente em outra passagem: "os relatos jornalísticos não costumam escrever tendo em vista a posteridade, senão tendo em vista a curiosidade humana" (PEUCER, 2001). Para o estudioso a curiosidade pelas notícias está mais próxima ao senso comum do que ao conhecimento rigoroso.

O autor destaca, no entanto, que para além de seu conteúdo as notícias possuem um caráter social inegável, pois promovem a interação entre os sujeitos e a sensação de comunhão na vida social através do compartilhamento da "novidade".

Com efeitos, o afã de saber coisas novas é tão grande que cada vez os cidadãos se encontram em encruzilhadas e nas vias públicas, perguntam: o que há de novo? A fim de satisfazer a curiosidade humana tem se imprimido de todo o modo novos relatos jornalísticos em diversos idiomas" (PEUCER, 2001).

Observando sua reflexão através das lentes atuais a reflexão de Peucer tem o mérito de destronar alguns mitos profissionais. Um deles é a ideia de que a reflexão sobre a prática jornalística seja de origem americana. A técnica narrativa fundante das notícias, posteriormente batizada de "lead" (que são seis perguntas que orientam o primeiro parágrafo do texto jornalístico: o que, quem, quando, onde, como e porque), por exemplo, já é formulada por Peucer em sua tese. Em seu texto ele transpõe as orientações da narrativa conceituadas originalmente por Marco Túlio Cícero (orador e filósofo da Roma, 400 anos antes da era cristã) para a prática noticiosa.

Entre a orientação e a descrição Peucer esforça-se em sugerir meios adequados para evitar os erros que presenciava nos periódicos de sua época. Inaugurando uma espécie de primeiro "manual de redação" jornalística. São mais do que orientações narrativas, mas a proposição mesmo de uma ética para a prática 
noticiosa. Há um momento em que aconselha os noticiaristas a evitarem o sensacionalismo; não publiquem informações sigilosas e estratégicas do poder; não firam os bons costumes e escolham assuntos relevantes.

A leitura de sua tese é uma experiência que desvela a atemporalidade de suas formulações. O que corrobora para a hipótese de que existem elementos universais na prática jornalística que a caracterizam como um conhecimento particular.

\section{O jornalismo na era moderna}

Os séculos 19 e 20 irão presenciar uma forte expansão do Jornalismo na vida cotidiana e política como um campo profissionalizado. São origens dessas transformações: a luta pela liberdade de opinião e de livre circulação de ideias e de opiniões, contra o absolutismo reinante em toda a Europa (séculos 16 e 17); a luta pela manifestação do pensamento e contra a censura. $\mathrm{Na}$ Inglaterra, a censura foi abolida entre 1695 e 1771; ainda na Inglaterra, em 1690, John Locke defenderá, no exame sobre formas de governo, que as pessoas com propriedade tinham o direito de dizer o que é liberdade ou não; François Marie Arouet de Voltaire (1694 - 1778) vai defender, ao longo de sua obra de mais de 50 volumes, a liberdade de expressão, inclusive através de panfletos, sugerindo que sejam elaborados de forma concisa e com máxima clareza e precisão. Argumenta em prol da tolerância, do limite público à autoridade da lei e, sobretudo, da liberdade de opinião. Em o Espírito das leis, Charles-Louis de Seconder, Barão de Montesquieu (1589-1755), defende a liberdade de expressão e do controle do poder pelo poder; em $O$ contrato social, Rousseau (1712 - 1778) defende que a sociedade será melhor se nela vingar a vontade geral e que a vontade geral dependeria da informação pública; as revoluções americana (1776) e francesa (1789) assinalaram que a livre circulação de pensamento e opinião seria um dos direitos fundamentais do homem. Trata-se da constituição de um imaginário social democrático em que a liberdade de imprensa adquire papel primordial, caso suprimida, implicaria na destruição das outras liberdades (ANCHIETA, FRANCISCO, 2007, p.4). 
A Revolução Industrial representou a etapa mais avançada do processo de capitalismo caracterizada pelo esvaziamento do campo na Europa e liquidação do setor feudal. $\mathrm{O}$ rápido crescimento das camadas intermediárias de administradores e ou técnicos qualificados que, necessariamente, tinham que estar informados. Concorre também para a expansão dos jornais e a histórica conformação do jornalismo, o crescimento da alfabetização da massa de trabalhadores. Na França, o analfabetismo atingia 22\% da população em 1872, caindo para quase 9\% em 1892 e descendo para cerca de 4\% perto do início da primeira guerra mundial em 1914.

Essas transformações culturais, tecnológicas, econômicas e políticas viabilizaram as crescentes tiragens dos jornais por edição. A comercialização dos espaços converterá a informação jornalística em uma mercadoria. A disputa por maior número de leitores tornou-se não só uma disputa por influência, mas também um duro combate por maior volume de anúncios.

É nesse novo contexto das práticas jornalísticas que outro importante teórico do jornalismo avança significativamente na compreensão da singularidade do conhecimento jornalístico. Robert Park ${ }^{1}$, o jornalista e sociólogo da Escola de Chicago, cidade americana que vivenciava um rápido crescimento, entrando no século 20 com mais de um milhão de habitantes e alcança três milhões e meio segundo o censo de 1930. Sua população era essencialmente de imigrantes estrangeiros, das mais diferentes nacionalidades. Era uma cidade industrial, moderna, experimentando embates políticos (grandes greves operárias) e o desenvolvimento artístico cultural. Dessa maneira, a sociologia de Chicago foi uma sociologia urbana, voltada, especialmente para a temática da cidade e dos meios de comunicação.

Mas, se esse é o espaço privilegiado para o nascimento da reflexão de Park sobre as notícias sua contribuição não se limita espacialmente e teoricamente a essa cidade e contexto. $\mathrm{O}$ jornalista pode ser localizado como um pragmatista que não necessariamente limita a pesquisa a uma experiência concreta, mas capaz de - por

\footnotetext{
${ }^{1}$ ANCHIETA, Isabelle. A notícia como forma de conhecimento segundo Robert Park. BOCC. Biblioteca On-line de Ciências da Comunicação, v. 2007, p. 01-11.
} 
meio da observação da prática - formular conceitos atemporais. "No método desenvolvido por Park, cada estudo de caso revestia-se de relevo porque tomava a forma da manifestação de um sintoma ou tendência em estágio de institucionalização na sociedade" (MACHADO, 2005, p.33).

Quando publica, em 1940, o artigo célebre A notícia como forma de conhecimento Park define um lugar próprio para o saber produzido pelo jornalismo.

a notícia não é um conhecimento sistemático como o das Ciências Físicas. Antes, na medida em que se refere a acontecimentos, semelha a História (...). Entretanto, a notícia não é história, e seus fatos não são fatos históricos. Não é a história porque, em primeiro lugar, se refere, em conjunto, a acontecimentos isolados e não procura relacioná-los nem com seqüências causais nem com seqüências teleológicas. A história não só descreve os acontecimentos, mas também procura colocá-los no lugar que lhes cabe na sucessão histórica (PARK, 1976, p. 174).

Outra característica singular ressaltada por Park para definir o jornalismo é a sua vinculação com o presente. $\mathrm{O}$ relato jornalístico só se legitima e se justifica no e para o presente. "Como forma de conhecimento, a notícia não cuida essencialmente nem do passado nem do futuro, senão do presente - e, por isso, foi descrita como 'presente especioso'. Pode-se dizer que a notícia só existe nesse presente" (PARK, 1976, p.175). Park demarca a diferença entre a notícia e a História argumentando que a primeira cumpre o seu papel na atualidade enquanto a segunda na posteridade. $\mathrm{O}$ jornalismo exerce sua função social ao anunciar o fato, a História o faz em ordená-lo dentro de critérios de relevância que lhe são próprios. "A notícia nos chega em circunstâncias ordinárias não como história continuada, mas como uma série de incidentes independentes" (PARK, 1976, p.175).

Park ressalta que tal função de narrar o presente situa-se em um contexto histórico particular de aceleração das descobertas tecnológicas e da mudança de costumes do sec. XX que conferem a notícia um papel importante. As "novidades" dão a impressão de uma aceleração do tempo e da necessidade de encontrar formas capazes de produzir conhecimento imediato. 
O papel da notícia assumiu uma importância antes acrescida que diminuída em confronto com outras formas de conhecimento como a História, por exemplo. Tão rápidas e drásticas são as mudanças nos últimos anos que o mundo moderno parece ter perdido a perspectiva histórica, e nós parecemos estar vivendo, dia a dia, no que descrevi anteriormente como presente especioso (PARK, 1976, p.184).

\section{Jornalismo: um conhecimento entre o senso comum e o saber especializado}

Robert Park elege em seu artigo uma comparação conceitual que será central na compreensão de sua tese sobre o conhecimento jornalístico. Distingue o "conhecimento de" e "conhecimento acerca de”. A comparação, realizada pioneiramente pelo psicólogo William James, é apropriada por Park para definir o jornalismo. Para ambos o "conhecimento de" seria uma "espécie de conhecimento que inevitavelmente adquirimos no curso de nossos encontros pessoais e de primeira mão com o mundo que nos rodeia" (PARK, 1976, p.169). Resumidamente, o "conhecimento de" seria o que entendemos por "senso comum".

Tal conhecimento, com efeito, pode ser concebido como forma de ajustamento orgânico ou adaptação, que representa a acumulação e, por assim dizer, a fusão de uma longa série de experiências. É essa espécie de conhecimento pessoal e individual que faz cada um de nós sentir-se à vontade no mundo que escolheu viver (...). Um conhecimento que se incorpora no hábito, no costume e, por fim - por algum processo de seleção natural, que não compreendemos plenamente - no instinto; uma espécie de memória ou hábito social (PARK, 1976, p.169).

Já o "conhecimento acerca de" trata-se do conhecimento racional que "baseia-se na observação e no fato, mas no fato verificado, rotulado, sistematizado e, finalmente, ordenado nesta ou naquela perspectiva, segundo o propósito do pesquisador" (PARK, 1976, p.171). O sociólogo conceitua ainda três formas mais recorrentes desse conhecimento: 1) Filosofia e Lógica, que se interessam pelas ideias; 2) História, que se interessa por acontecimentos e 3) Ciências Naturais ou de classificação, interessadas por coisas. 
A capacidade de ordenar o real que possui o mérito de tornálo inteligível acaba, por outro lado, em distanciá-lo das práticas cotidianas. Isso se dá porque o saber especializado se faz com base em artifícios, técnicas e jargões próprios, divorciados do senso comum. "A ciência, puramente intelectual, corre sempre o risco de tornar-se tão completamente alheia às coisas que, os símbolos com os quais opera, passam a ser meros brinquedos mentais" (PARK, 1976, p.172).

Apesar de não concluir com clareza seu raciocínio, Park parece indicar um "entre lugar" para o jornalismo situando-se como um terceiro elemento que emerge na interação entre "o conhecimento de" e "o conhecimento acerca de". Não é idêntico ao senso comum, por possuir um modo e processo próprio de selecionar, enquadrar, valorar e ordenar os acontecimentos em um tempo e espaço próprios da notícia (newsmaking ${ }^{2}$ ); muito menos pode se situar como um conhecimento com os rigores formais próprios da Ciência e da História, na medida em que busca dar comunicabilidade a sua narrativa. Nesse sentido Park afirma que "a função da notícia é orientar o homem e a sociedade num mundo real” (PARK, 1976, p.183)

\section{Conclusão}

\section{"Que todos entendam e que os eruditos respeitem", Tobias Peucer, 1690.}

A comparação entre obras fundadoras da discussão sobre o conhecimento jornalístico, a de Tobias Peucer na Alemanha do século 17 e Robert Park nos Estados Unidos do século 20 resulta em um duplo achado composto por mudanças e permanências. Mudança do estatuto do conhecimento jornalístico nas sociedades modernas. Mas, revelam também características universais da prática e da linguagem jornalística que, apesar da passagem do tempo, permaneceram.

\footnotetext{
${ }^{2}$ Uma das teorias do jornalismo que abrange várias temáticas. Entre elas: as rotinas de produção; a cultura profissional e a organização do trabalho jornalístico. Perspectiva construcionista e sociológica do trabalho jornalístico que tem como principais autores Michael Shudson, Gaye Tuchman e Nelson Traquina.
} 
Das mudanças de estatuto social do jornalismo percebemos a transição de uma narrativa concebida como marginal no século 17 frente à História para observarmos a emergência, ainda sob suspeita, das notícias. Em Park do 20, o ambiente é outro. Um contexto em que as publicações já estavam consolidadas como mediação das sociedades modernas capitalistas. Não há em Park um tom crítico ao jornalismo, como acontece em Peucer. Esse último revela, por sua oscilação, o ambiente social do nascimento do jornalismo em meio a um momento de profundas transformações sociais, econômicas e religiosas. Do qual o jornalismo é fruto, mas que protagoniza um lugar na circulação da nova ideologia burguesa laica e democrática.

Os textos funcionam, nesse sentido, como sintomas dos tempos. Documentações da crise das grandes narrativas, em que vemos surgir um novo lugar para a compreensão do jornalismo como uma forma legítima de conhecimento sobre o presente. Um conhecimento que adquire, paulatinamente, centralidade nas sociedades modernas.

O fato de o jornalismo ser, dentre os discursos, o menos esotérico, ou o mais próximo do senso comum não significa que sejam sinônimos. $\mathrm{O}$ que o jornalismo realiza é a tradução de conhecimentos especializados e complexos para uma linguagem de alta comunicabilidade. Compara números abstratos com referencias cotidianas, humaniza dados de pesquisa elegendo personagens, concilia fontes especializadas com cidadãos comuns. Há nessa interação entre dados e vida cotidiana, entre especialistas e não especialistas a emergência de um saber voltado e interessado no presente e na orientação do homem na vida real e cultural de sua sociedade. Sua função e pretensão limitam-se nesse tempo e espaço, o que torna seu discurso fragmentado, mas nem por isso menos relevante do que o Histórico. São diferentes. Cumprem funções e dão conta de ritmos diversos da passagem do tempo.

Concluindo podemos afirmar que o jornalismo é um conhecimento singular na medida em que possui: 1) uma ordenação do tempo particular. $\mathrm{O}$ jornalismo orienta-se por uma narrativa do presente e mesmo quando volta ao passado, esse retorno visa iluminar ou elucidar um fato atual. Um "presente especioso" segundo 
Park, na medida em que adquire um enquadramento noticioso. Nesse sentido o jornalismo constrói uma segunda ordem temporal sobreposta ao tempo social, através de rotinas diárias de trabalho cadenciadas por "deadlines" e planejamentos de cobertura (pauta). Assim, mais do que seguir o tempo social, o jornalismo age em um tempo ou ciclo próprio: "o dia noticioso". Dia, esse, marcado por faixas de tempo ou "time slots" (Schlesinger, IN: TRAQUINA, 1993, p.183); 2) um processo particular de seleção dos acontecimentos sociais. Tanto em uma esfera subjetiva (gatekeeper); quanto em um nível organizacional verifica-se que há entre o acontecimento e a notícia um processo de filtragem, escolha e hierarquização dos acontecimentos que são ou não considerados publicamente relevantes. Hierarquia, essa, definida por critérios e filtragens individuais e organizacionais; 3) uma narrativa própria. O que implica considerar suas técnicas particulares que incluem: o processo de hierarquização e seleção dos acontecimentos (os valores-notícia); o lead; a pirâmide invertida e o uso de pontuações objetivas como as aspas, o ponto e as vírgulas, evitando as expressões textuais subjetivas, como reticências, exclamações e interrogações. Nesse sentido a linguagem jornalística é uma organização simbólica particular; 4) Relações particulares com o poder e o público; especialmente localizadas na relação entre jornalistas com as fontes noticiosas. A ideia é que o poder ideológico seria reproduzido na notícia através do uso de "fontes acreditadas" que defenderiam interesses políticos e econômicos próprios. $\mathrm{O}$ jornalismo não pode ser percebido como um relato imparcial já que uma série de "parcialidades" está em jogo na interação e tensão com as fontes noticiosas e o público.

O jornalismo é, portanto, um subsistema inserido e em diálogo com um sistema maior: o seu contexto sócio histórico, econômico e cultural. E, como subsistema, o jornalismo possui uma "relativa autonomia" em relação à sociedade que se insere, já que possui um "modus operandi" próprio que se superpõe e interage com esse sistema. Dessa forma não corremos o risco nem de superestimar o poder da mídia - que é condicionada culturalmente - nem muito menos menosprezamos sua importância - já que possui relativa autonomia no sistema social além de ter uma posição institucionalmente importante e reconhecida nele. 
Como todo subsistema, o da mídia conta com relativa autonomia (isto é, independente do controle de grupos e instituições de outros subsistemas) para a produção de comunicação, através de códigos e de semânticas específicas, em ambientes de ação ordenados e validados por critérios próprios. (...) Sob tal ótica, a comunicação deixa de ser entendida como meio, e passa a ser entendida como ambiente de ação (MAIA, p.21, 2006).

Esse ambiente de ação, o jornalismo, deve ser compreendido, julgado e analisado tendo em vista seu ethos e função social. Não faz sentido avaliar seu lugar dentre as áreas de conhecimento, comparando-o com campos de saber que possuem intenções e papéis diversos na sociedade. Isso seria adotar um olhar distorcido sobre as singularidades do conhecimento produzido pelo jornalismo, incapaz de perceber suas possibilidades. Mesmo porque o jornalismo possui uma característica que definitivamente o distingue das demais áreas: a publicização do saber através de uma linguagem de alta comunicabilidade. Em 1711, os editores ingleses do The Spectator, Richard Steele e Joseph Addison, já haviam percebido tal vocação do jornalismo. "Trazer a filosofia para fora das instituições acadêmicas para ser tratada em clubes e assembleias, em mesas de chá e café" (BURKE, p.78, 2004). Eis seu desafio: ser simples, sem ser simplório ou nas palavras de Peucer: "Que todos entendam e que os eruditos respeitem" (PEUCER, 1690).

\section{Referências}

ALSINA, Miguel Rodrigo. La producción de la noticia: estudio sobre la construcción de la realidad. Barcelona, Gustavo Gili, 1983.

ANCHIETA, Isabelle. A notícia como forma de conhecimento segundo Robert Park. BOCC. Biblioteca On-line de Ciências da Comunicação, v. 2007, p. 01-11, 2007.

ANCHIETA, Isabelle; FRANCISCO, Dalmir. Uma história do Jornalismo. Grupo de pesquisa: Jornalismo Cognição e Realidade. Belo Horizonte: UFMG, 2007.

BERGER, Peter. LUKMAN, Thomas. A construção social da realidade: tratado de sociologia do conhecimento. Petrópolis: Vozes, 1985.

BURKE, Peter; BRIGHS, A. Uma história social da mídia: de Gutenberg à Internet. Rio de Janeiro: Jorge Zahar, 2004. 
CERTEAU. Michel de. A invenção do cotidiano. Vol.1. Artes de fazer. Petrópolis: Vozes, 1994.

FRANÇA, Vera. Comunicação, sociabilidade e cotidiano: o fio de Ariadne, a palavra da rua. In: FAUSTO NETO, A; PINTO, M. (Org.). O indivíduo e as mídias. Rio de Janeiro, 1996.

FILHO, Adelmo Genro. O segredo da pirâmide: para uma teoria marxista do jornalismo. Porto Alegre, Tchê, 1987.

LAGE, Nilson. Ideologia da notícia. Petrópolis: Vozes, 1979.

LYOTARD, Jean-François. O pós-moderno. Rio de Janeiro: José Olympio, 1993.

MAFFESOLI, Michel. Elogio da razão sensível. Petrópolis: Vozes, 1998.

MAIA, Rousuley. Mídia, esfera pública e identidades coletivas. Belo Horizonte: UFMG, 2006.

MEDISTSCHE, Eduardo. O conhecimento do jornalismo. Florianópolis: UFSC, 1992.

MOUILLAUD, Maurice. O jornal: da forma ao sentido. Brasília: Editora UnB, 2002.

NIETZSCHE, Friedrich. Vontade de Potência. São Paulo: Escala, 2006. Coleção Mestres Pensadores.

PARK, Robert. A notícia como forma de conhecimento. Steinberg-Meios de comunicação de massa. São Paulo: Cultrix, 1976.

PEUCER, Tobias. Relatos jornalísticos. Revista Comunicação $\mathbb{E}$ Sociedade, n 36. São Paulo: UMESP, 2001.

MACHADO, Elias. O pioneirismo de Robert E. Park na pesquisa em Jornalismo. Revista Estudos em Jornalismo e mídia, v.II, n.1. Florianópolis: Insular, 2005.

SCHLESINGER, Philip. Os jornalistas e a sua máquina do tempo. In:

TRAQUINA, Nelson (org.). Jornalismo: questões, teorias e "estórias". Lisboa:Vega, 1993

SOUSA, Jorge Pedro. Tobias Peucer: progenitor da Teoria do Jornalismo. Disponível em <www.bocc.ubi.br>. Acesso em; 25 jun. 2005. 
TAMBOSI, Orlando. Informação e conhecimento no jornalismo. Estudos em Jornalismo e Mídia. Florianópolis: Insular, v.2, 2005.

TRAQUINA, Nelson. Jornalismo: questões, teorias e estórias. Lisboa: Veja 1993.

WOLF, Mauro. Teorias das comunicações de massa. São Paulo: Martins Fontes, 2003.

VATTIMO, Gianni. A sociedade transparente. Lisboa: Olhos d'água: 1992.

Recebido: 25.08.2010 Aceito: 30.05 .2011 